\title{
High-Potency Marijuana Impairs Executive Function and Inhibitory Motor Control
}

\author{
Johannes G Ramaekers*,', Gerhold Kauert ${ }^{2}$, Peter van Ruitenbeek', Eef L Theunissen', Erhard Schneider ${ }^{3}$ \\ and Manfred R Moeller ${ }^{4}$
}

'Experimental Psychopharmacology Unit, Department of Neurocognition, Faculty of Psychology, Maastricht University, Maastricht, The Netherlands; ${ }^{2}$ Department of Forensic Toxicology, Institute of Legal Medicine, Goethe University of Frankfurt, Frankfurt, Germany;

${ }^{3}$ Landeskriminalamt, Kriminaltechnisches Institut, Baden-Württemberg, Germany; ${ }^{4}$ Unikliniken des Saarlandes, Homburg, Germany

\begin{abstract}
Human performance studies have usually relied on low-potency marijuana (4\% THC) for determining THC-induced impairment. The present study was designed to assess the effects of high-potency marijuana (I3\% THC) on human performance. In all, 20 recreational users of marijuana participated in a double-blind, placebo controlled, three way cross-over study. The treatments consisted of single doses of 0,250 , and $500 \mu \mathrm{g} / \mathrm{kg}$ THC. Performance tests were conducted at regular intervals between 15 min and $6 \mathrm{~h}$ postsmoking and included measures of motor control (Critical tracking task), executive function (Tower of London) motor impulsivity (Stop signal task), and risk taking (lowa gambling task). THC significantly impaired performance in the Critical tracking task and decreased the number of correct decisions in the Tower of London task. In addition, THC significantly increased stop reaction time and the proportions of commission and omission errors in the Stop signal task. THC-induced impairments lasted up to $6 \mathrm{~h}$ postsmoking as indicated by the absence of a THC $\times$ Time after smoking interaction. Effect sizes for performance impairments produced by $\mathrm{THC} 250 \mu \mathrm{g} / \mathrm{kg}$ were relatively low but generally increased by a factor of two in case of THC $500 \mu \mathrm{g} / \mathrm{kg}$. These data suggest that high potency marijuana consistently impairs executive function and motor control. Use of higher doses of THC in controlled studies may offer a reliable indication of THC induced impairment as compared to lower doses of THC that have traditionally been used in performance studies. Neuropsychopharmacology (2006) 3 I, 2296-2303. doi: I 0. I038/sj.npp. I 30 I068; published online 29 March 2006
\end{abstract}

Keywords: THC; potency; cognition; impulsivity; motor control; acute

\section{INTRODUCTION}

The acute effects of $\Delta^{9}$-tetrahydrocannabinol (THC) on isolated cognitive functions have been assessed in numerous experimental studies employing within subject, double blind, placebo controlled designs. These have generally shown that THC in doses up to $300 \mu \mathrm{g} / \mathrm{kg}$ (ie about $15-$ $20 \mathrm{mg}$ ) causes a dose-related reduction in performance at laboratory tasks measuring memory, divided and sustained attention, reaction time, tracking and motor function (reviews: Ameri, 1999; Hall and Solowij, 1998; Iversen, 2003; Lichtman et al, 2002; Ramaekers et al, 2004). One of the most consistently reported behavioural effects of THC is a disruption in the free recall of previously learned information. Recall of items learned before cannabis use is generally not affected, suggesting that THC impairs

\footnotetext{
*Correspondence: Dr JG Ramaekers, Experimental Psychopharmacology Unit, Department of Neurocognition, Faculty of Psychology, Maastricht University, PO Box 616, 6200 MD Maastricht, The Netherlands, Tel: + 31 43388 I95।, Fax: + 31433884 I25,

E-mail: j.ramaekers@psychology.unimaas.nl

Received 6 October 2005; revised 14 February 2006; accepted 17 February 2006

Online publication: 2 I February 2006 at http://www.acnp.org/citations/ Npp022 1060506 I0/default.pdf
}

learning and the acquisition of information but not its retrieval from memory (Curran et al, 2002; D'Souza et al, 2004; Hampson and Deadwyler, 1999; Leweke et al, 1998).

However, the severity of such performance deficits has also been challenged by a number of studies that failed to demonstrate any substantial impairment of simple psychomotor function or complex cognitive task performance after acute doses of THC (Fant et al, 1998; Hart et al, 2001; Heishman et al, 1997). Some researchers have noted that marijuana smokers are very much aware of their intoxication and take appropriate precautions to compensate for the impairing effects of marijuana smoking. For example, onthe-road and simulator driving studies have found that cannabis drivers tended to reduce their driving speed and drive at greater headway while under influence of THC (Robbe, 1994; Sexton et al, 2000; Smiley, 1999). These results have been interpreted to indicate that marijuana causes drivers to be more cautious and reduce risk taking behaviours, as compared to alcohol-intoxicated drivers (Robbe, 1994; Sexton et al, 2000; Smiley, 1999).

A potential drawback that may pertain to marijuana studies on human performance to date is that doses of THC that have been administered are less than those frequently found in marijuana cigarettes or sought by marijuana smokers to achieve their desired high. Most controlled 
studies have relied on marijuana cigarettes that were provided by the US National Institute of Drug Abuse that on average contained up to $4 \%$ of THC (about $15-20 \mathrm{mg}$ THC). Over the last 15 years, however, mean THC content of marijuana breeds in the US and the EU has risen from about $5 \%$ to about $10 \%$, particularly since the introduction of indoor hydroponic cultivation techniques (ElSohly, 2004; King et al, 2004, 2005). Higher concentrations of up to 20 or $40 \%$ THC have been observed in sinsemilla or hash oil, respectively (ElSohly, 2004; King et al, 2004). A recent survey in the Netherlands among 411 marijuana smokers indicated that smoking high-potency marijuana cigarettes will, in general, also increase the average consumption of THC. As much as $46 \%$ of the smokers indicated that they would not titrate their smoking routine to achieve their desired high but would inhale as much as possible when offered high-potency marijuana (Korf et al, 2004). Previous laboratory studies have also indicated that subjects fail to regulate their intake of marijuana smoke in response to substantial changes in marijuana THC content (Chait, 1989) and that subjects choose to smoke high-potency marijuana significantly more often than low-potency marijuana (Chait and Burke, 1994). Previous results from marijuana studies on human performance may thus present a conservative estimate of detrimental effects that might be expected for some of the higher doses that are common among marijuana smokers today.

The aim of the present study was to assess the effects of a THC-rich breed (13\%) of marijuana on performance in a placebo controlled, double blind study design. Performance tasks included measures of neuropsychological functions that have been claimed to be relatively insensitive to cannabis intoxication: that is executive function, risk taking and motor control (Robbe, 1994; Heishman et al, 1997; Fant et al, 1998; Sexton et al, 2000; Smiley, 1999; Hart et al, 2001). The THC level in the present cannabis breed was greater than can be legally obtained for research in the US and is less common with regards to general use in the US. However in Europe, Canada and Australia high-potency breeds are more common with regard to general use as well as medicinal use. In the Netherlands, $13 \%$ THC is a standard potency for marijuana cigarettes sold at pharmacies for medical use.

Cannabis cigarettes were tailored to each individual subject to represent weight calibrated doses of $250 \mu \mathrm{g} / \mathrm{kg}$ THC and $500 \mu \mathrm{g} / \mathrm{kg}$ THC. The total amount of THC consumed in both THC conditions were, respectively, 17.5 and $35 \mathrm{mg}$ assuming an average body weight of $70 \mathrm{~kg}$. The former dose is about equivalent to the highest dose that has traditionally been administered in previous marijuana studies on the effects of marijuana on performance (Curran et al, 2002; Fant et al, 1998; Hart et al, 2001; Heishman et al, 1997; Lane et al, 2005; Liguori et al, 2002, 2003; McDonald et al, 2003), whereas the latter dose exceeds the traditional 'highest dose' by a factor of 2 . Task performance was assessed at fixed intervals during $6 \mathrm{~h}$ after smoking.

\section{METHODS}

\section{Subjects}

Sample size was determined by a power calculation in order to obtain a statistical power of $90 \%$ for a two-sided significance level of $5 \%$. In all, 20 recreational cannabis users (14 males, six females, all Caucasian) aged 19-29 years participated in the present study. Body weight of the subjects ranged from 55 to $93 \mathrm{~kg}$ with a mean of $72.7 \mathrm{~kg}$. All subjects were light users of cannabis. Mean (SD) frequency of cannabis use was 3.4 (3.0) times per month and their mean duration of cannabis use was 3.9 (2.3) years. Five subjects attested to occasional use of stimulants. In addition, 19 subjects were regular users of caffeine and alcohol and 17 subjects were regular smokers. Their mean (SD) consumption of alcohol and caffeine drinks per week was 12.4 (8.1) and 18.1 (14.4), respectively, and their average amount (SD) of cigarettes per week was 92.5 (51.1).

Subjects were recruited through advertisements in coffee shops or local newspapers. Initial screening comprised of a questionnaire on medical history. Subjects who were selected were examined by the medical supervisor who also checked vital signs and took blood and urine samples. Standard blood chemistry, haematology and drug screen tests were conducted on these samples. Inclusion criteria were: experience with the use of cannabis (at least five times in the previous 12 months; free from psychotropic medication; good physical health as determined by medical examination and laboratory analysis; absence of any major medical, endocrine, and neurological condition; normal weight, body mass index (weight/length ${ }^{2}$ ) between 18 and $28 \mathrm{~kg} / \mathrm{m}^{2}$; written Informed Consent. Exclusion criteria were: history of drug abuse (including daily use of marijuana) or addiction; pregnancy or lactation or failure to use reliable contraceptives; excessive drinking $(>20$ standard alcoholic consumptions a week); hypertension (diastolic $>100$; systolic $>170$ ) or history of psychiatric disorders.

The study was conducted according to the code of ethics on human experimentation established by the declaration of Helsinki (1964) and amended in Edinburgh (2000). All subjects were fully informed of study procedures, adverse reactions to drug treatments, legal rights and responsibilities, expected benefits of a general scientific nature, and their right for voluntary termination without penalty or censure. All subjects gave their informed consent, in writing. A permit for obtaining, storing and administering marijuana was obtained from the Dutch drug enforcement administration. All subjects received a fixed fee per treatment condition and an additional monetary incentive if they completed all treatment conditions.

\section{Design, Doses, and Administration}

The study was conducted according to a double-blind, placebo-controlled, 3-way cross-over design. Subjects received THC placebo, $250 \mu \mathrm{g} / \mathrm{kg}$ THC and $500 \mu \mathrm{g} / \mathrm{kg}$ THC. Treatment orders were randomly assigned to subjects according to a balanced block design. A minimum washout of 7 days transpired between treatments. Smoking started in the morning of test days (between 0920 and $0940 \mathrm{am}$ ) and lasted for about $10 \mathrm{~min}$. The cigarettes were prepared beforehand for each individual from stock provided by the Dutch Bureau for Medicinal Cannabis. Marijuana cigarettes were prepared from batches containing $13 \%$ THC, a standard potency for marijuana sold at Dutch pharmacies for medical use. They were cut to a length 
appropriate for each subjects' body weight. Placebo cigarettes equalled weight and size of active marijuana cigarettes, but differed in taste as they contained no active THC. Subjects were instructed to smoke the cigarette according to a fixed procedure in order the minimize the subject's possibility of dose titration and to increase optimal absorption of THC (Robbe, 1994): that is, inhale for $4 \mathrm{~s}$, hold breath for $10 \mathrm{~s}$ and exhale/break for $15 \mathrm{~s}$. This sequence was repeated until the cigarettes were smoked as completely as possible. Mean (SD) number of puffs smoked from the cigarette in the placebo, THC 250 and THC500 condition were 22 (3.4), 24 (3.8), and 25 (4.3), respectively.

\section{Procedures}

Subjects were asked to refrain from any drugs during the study period. Subjects were not allowed to use alcohol on the day prior to an experimental session and were requested to arrive at experimental sessions well rested. Drug and alcohol screens were performed prior to experimental sessions upon arrival of the subject. Drugs screens assessed for the presence of morphine, cocaine, marijuana, methampethamine, and amphetamine. THC or THC placebo cigarettes were only administered if a subject had passed the alcohol and drug screen on a given test day. In case of a positive drug screen, subjects were sent home to return to the laboratory at a later time. Four subjects tested positive for cannabis in urine prior to cannabis or cannabis placebo smoking. These subjects were sent home to return to our laboratory at a later time. Subjects were given a standardized breakfast prior to smoking. Performance tests were conducted at fixed intervals during $6 \mathrm{~h}$ postsmoking. The Critical tracking task was conducted at $15 \mathrm{~min}, 1 \frac{1}{4}, 3 \frac{1}{4}$, and $5 \frac{1}{4} \mathrm{~h}$ postdosing; a Stop signal task was conducted at $30 \mathrm{~min}$, $1 \frac{1}{2}, 3 \frac{1}{2}$, and $5 \frac{1}{2} \mathrm{~h}$ post-dosing; the Tower of London was conducted at $45 \mathrm{~min}, 1 \frac{3}{4}$, and $5 \frac{3}{4} \mathrm{~h}$ postdosing, and the Iowa gambling task was conducted once at $1 \mathrm{~h}$ postdosing. Subjective high was assessed at $15 \mathrm{~min}, 1 \frac{1}{4}, 3 \frac{1}{4}$, and $5 \frac{1}{4} \mathrm{~h}$ postdosing. Subjects received a training session prior to onset of the experimental sessions in order to familiarize them with the tests and procedures and minimize practice effects. Training in Critical tracking and Stop signal task performance continued until the subject had performed each task with $<5 \%$ variance from the average measured over three trials. Performance on the Iowa gambling task and the Tower of London task show little practice effect and were administered once during training.

\section{Performance and Subjective Test}

Critical tracking task. CTT measures the subject's ability to control a displayed error signal in a first-order compensatory tracking task. Error is displayed as a horizontal deviation of a cursor from the midpoint on a horizontal, linear scale. Compensatory joystick movements null the error by returning the cursor to the midpoint. As the task progresses the velocity of the cursor's deviation increases. The subject's compensatory response increases in frequency with an increasing phase lag. Control is lost at the point where the compensatory response lags the cursor's last movement by 180 degrees. The response frequency at this point is defined as the critical frequency or $\lambda_{\mathrm{c}}$. The test includes five trials of which the lowest and the highest score are removed. The average of the remaining scores is taken as the final score. The Critical tracking task measures the perceptual-motor delay lag (ie psychomotor control) during a closed loop operation (Jex et al, 1966).

The Tower of London. The original version of the Tower of London (TOL) consists of three colored balls, which must be arranged on three sticks to match the target configuration on a picture while only one ball can be moved at a time (Shallice, 1982). The present version consists of computergenerated images of begin- and end-arrangements of the balls. Every time a ball is moved counts as one step. The subject decides as quickly as possible, whether the endarrangement can be accomplished in 2, 3, 4, or 5 steps from the beginning arrangement by pushing the corresponding number coded button (Veale et al, 1996). Nine different versions of this test were assessed and balanced over test days and time of assessments. The Tower of London is a decision making task that measures executive function and planning. The total number of correct decisions and planning time are the main performance measures.

The Stop signal task. The task requires subjects to make quick key responses to visual go signals and to inhibit any response when a visual stop signal is suddenly presented. Many versions of the Stop signal paradigm exist. The current test is adapted from an earlier version of Fillmore et al (2002) and has been validated for showing stimulant and sedative drug effects (Ramaekers and Kuypers, 2006). The go signals are four $1.5 \mathrm{~cm}$ letters $(\mathrm{ABCD})$ presented one at a time in the center of a computer screen. Subjects are required to respond to each letter as quickly as possible by pressing on of two response buttons. One button is pressed to indicate that ' $A$ ' or ' $C$ ' appeared and the other to indicate ' $\mathrm{B}$ ' or ' $\mathrm{D}$ '. A single test consists of 176 trials in which each of the four letter stimuli is presented equally often. A stop signal occurred in 48 trials during a test. The stop signal consists of visual cue, that is, ' $*$ ', that appears in one of the four corners of the screen. Subjects are required to withhold any response in case a stop-signal is presented. Stop signals are presented 12 times at each of the four delays after the onset of a letter: 50, 150, 250 and $350 \mathrm{msec}$. Dependant variables are the proportion of commission errors on stop trials (ie inhibition failures), omission errors (false alarms) on go trials and the reaction times on go and stop signal trials (ie stop reaction time). Stop reaction time to stop signal trials represents the estimated mean time required to inhibit a response. Stop reaction time was calculated by subtracting the stop signal delay from the go reaction time associated with $n$th percentile of the RT distribution. The $n$th percentile corresponds to the percentage of commission errors (Logan, 1994). The Stop signal task measures motor impulsivity, which is defined as the inability to inhibit an activated or precued response leading to errors of commission.

The Iowa gambling task. The subject sees four decks of cards on a computer screen labeled A, B, C, and D at the top end of each deck. With a mouse, the subject can click on a card on any of the four decks. Each deck of cards is 
programmed to have 40 cards. The gains and losses for each card selection are set so that in each block of 10 cards from deck A or deck B over the course of trials there is a total gain of $\$ 1000$ (interspersed with unpredictable losses totalling \$1250). For decks C and D, the gains and losses for each card selection are set so that in each block of 10 cards there is a total gain of $\$ 500$, interrupted by losses totaling \$250 (gains and losses all refer to virtual money). Thus decks A and B are 'disadvantageous' in the long term, while decks $\mathrm{C}$ and $\mathrm{D}$ are 'advantageous' in the long term. One dependent measure is collected from this task: net score (total \# of cards picked from C and D minus total \# of cards picked from A and B). Parallel versions of the gambling task are used over three treatment sessions. The Iowa gambling task measures decision making and risk sensitivity as defined by the inability to anticipate and reflect on the consequences of decision-making (Bechara et al, 2000, 2001).

Subjective high. Subjects were required to rate their feeling of 'high' as a percentage (0-100) of the maximum ever experienced on a $100 \mathrm{~mm}$ visual analog scale.

\section{Pharmacokinetic Assessments}

Blood samples $(5 \mathrm{ml})$ were taken right after smoking and at 1,3 , and $6 \mathrm{~h}$ postsmoking. They were placed on ice immediately, centrifuged later and frozen at $-20^{\circ} \mathrm{C}$ until analyses for pharmacokinetic assessments. THC concentrations were determined in the corresponding serum samples using solid phase extraction and gas chromatography with mass spectrometric detection with a limit of quantification of $0.5 \mathrm{ng} / \mathrm{ml}$ (Steinmeyer et al, 2002).

\section{Statistics}

Data were analyzed by means of GLM repeated measures MANOVA with THC (3 levels), Time after smoking (3 or 4 levels) and their interaction as main factors. In case of a significant overall effect of THC or THC $\times$ Time after smoking, follow-up tests were conducted to test for differences among the levels of the factor THC. These were simple GLM contrasts for comparing performance between THC treatment conditions and placebo. The alpha criterion level of significance was set at $p=0.05$. In addition, estimates of effect size were calculated for every contrast by eta-squared statistics. Effect size in GLM is a measure of the degree of association between effect and the dependent variable or the proportion of variance in the dependent variable that is attributable to an effect.

\section{RESULTS}

Complete data sets $(N=20)$ were collected for the Critical tracking task, the Tower of London, the Iowa gambling task and subjective rating of high. In the case of the Stop signal task, data sets of nine subjects were incomplete due to technical malfunctions. Only complete data sets entered the statistical analyses.

A summary of significant treatment effects and their associated effect sizes are shown in Table 1.

On the Critical tracking task, MANOVA indicated a significant overall effect of THC on lambda-c $\left(\mathrm{F}_{2,18}=9.41\right.$;

Table I Summary of Significant THC Effects and Associated Effect Sizes

\begin{tabular}{|c|c|c|c|c|c|c|}
\hline \multirow{2}{*}{ Tests and dependant variables } & \multirow{2}{*}{\multicolumn{2}{|c|}{ Overall $p$-values }} & \multicolumn{4}{|c|}{ Contrasts } \\
\hline & & & \multicolumn{2}{|c|}{ THC 500 vs PLA } & \multicolumn{2}{|c|}{ THC 250 vs PLA } \\
\hline \multicolumn{7}{|l|}{ Critical tracking task } \\
\hline \multicolumn{7}{|l|}{ Tower of London } \\
\hline Correct decisions & 0.005 & - & 0.002 & 0.40 & 0.016 & 0.16 \\
\hline RT (planning time) & - & 0.025 & - & - & - & - \\
\hline \multicolumn{7}{|l|}{ Stop signal task } \\
\hline RT Go trials & - & - & & & & \\
\hline \multicolumn{7}{|l|}{ lowa gambling task } \\
\hline Ratio (good/bad) & - & - & & & & \\
\hline Subjective high & 0.000 & 0.004 & 0.000 & 0.75 & 0.000 & 0.65 \\
\hline
\end{tabular}




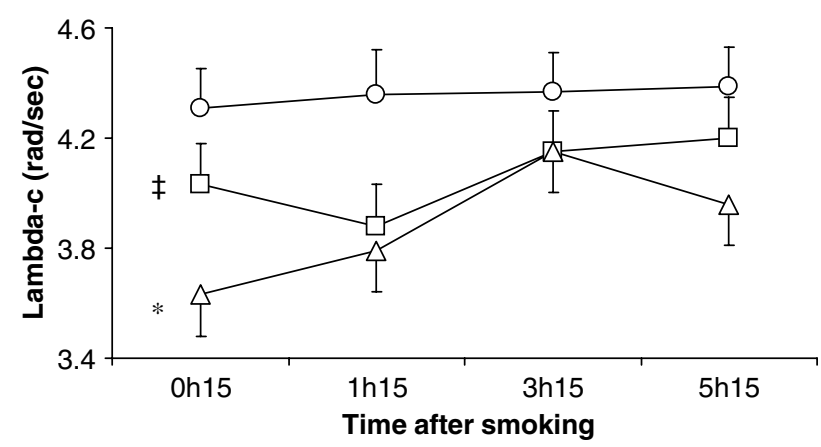

Figure I Mean (SE) lambda-c in the Critical tracking task for each treatment condition as a function of time after smoking. Legend: THC $500=\triangle ;$ THC $250=\square ;$ PLA $=0$. Symbols indicate significant $(p<0.05)$ contrasts between THC500 and PLA (*) and between THC250 and PLA $(\ddagger)$.

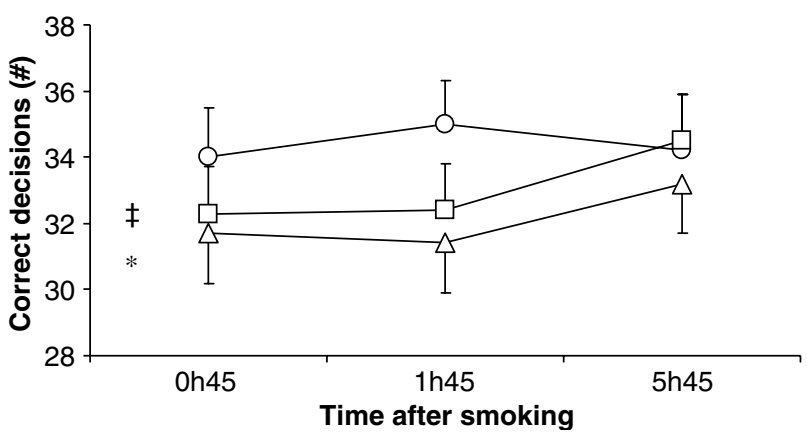

Figure 2 Mean (SE) number of correct decisions in the Tower of London task for each treatment condition as a function of time after smoking. Legend: THC $500=\triangle$; THC $250=\square ; P L A=O$. Symbols indicate significant $(p<0.05)$ contrasts between THC500 and PLA $(*)$ and between THC250 and PLA ( $)$.

$p=0.002)$. There was no significant interaction between THC and Time after smoking. Separate THC-placebo or THC500-THC250 comparisons indicated that both doses of THC significantly decreased tracking performance throughout a $6 \mathrm{~h}$ period $(p<0.031)$. Mean (SE) lambda-c in every treatment condition is shown in Figure 1.

Overall, the number of correct decisions in The Tower of London task was significantly affected by THC $\left(\mathrm{F}_{2,18}=7.25\right.$; $p=0.005$ ) but not by THC $\times$ Time after smoking. Separate THC-placebo and THC500-THC250 contrasts indicated that both doses of THC significantly decreased the number of correct decisions over time as compared to placebo $(p<0.016)$. Mean (SE) number of correct decisions in every treatment condition is shown in Figure 2. Planning time was not affected by THC, but the interaction between THC $\times$ Time after smoking reached significance $\left(\mathrm{F}_{4,16}=\right.$ $3.73 ; p=0.025)$. Visual inspection of the means in each of the treatment conditions suggested a larger planning time at $45 \mathrm{~min}$ after smoking the high dose of THC relative to placebo. However, separate drug-placebo contrasts did not reveal any significant differences between both THC doses and placebo.

In the Stop signal task, significant overall effects of THC were found on measures of stop reaction time commission errors and omission errors $\left(\mathrm{F}_{2,9}>3.73 ; p<0.032\right)$. There was no interaction between THC and Time after smoking.
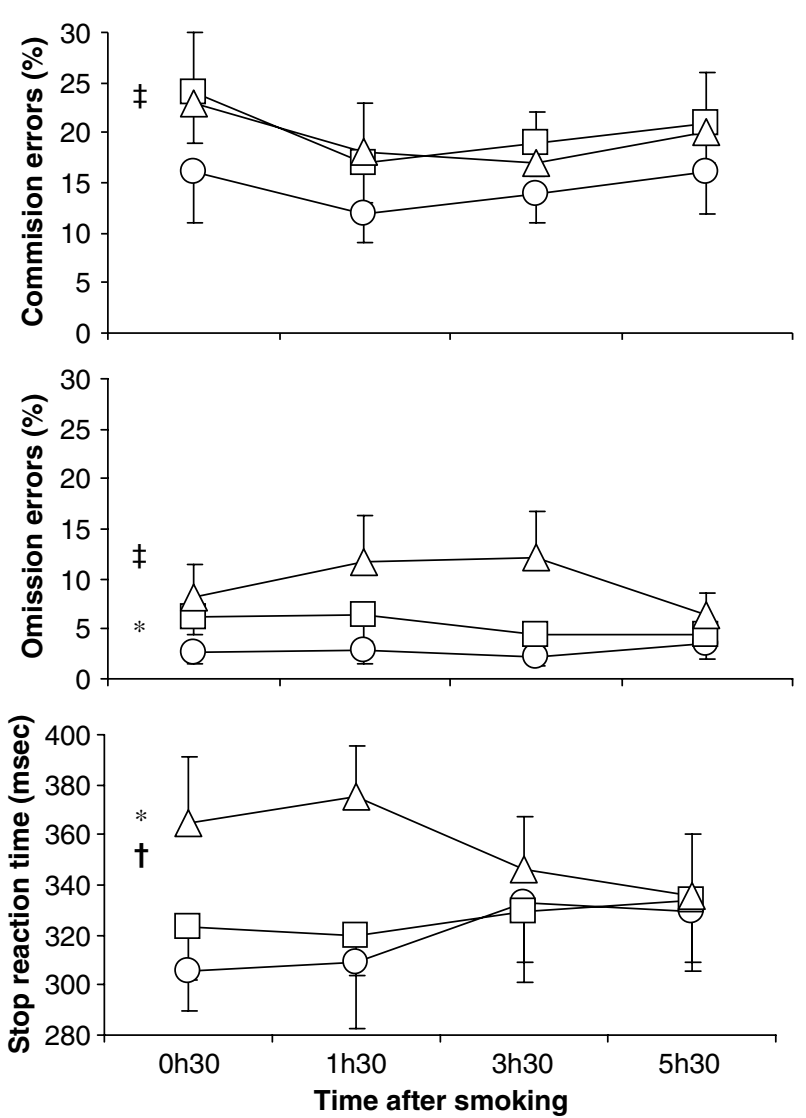

Figure 3 Mean (SE) stop reaction time, omission and commission errors in the Stop signal task for each treatment condition as a function of time after smoking. Legend: THC $500=\triangle$; THC $250=\square ;$ PLA $=0$. Symbols indicate significant $(p<0.05)$ contrasts between THC500 and PLA $(*)$, THC250 and PLA ( $\ddagger)$ and between THC500 and THC250 (†).

Separate THC-placebo comparisons revealed that THC500 increased stop reaction time and the number of omission errors $(p<0.021)$, whereas THC250 increased the number of commission and omission errors $(p<0.011)$. Stop reaction time also significantly differed between both THC treatments $\left(\mathrm{F}_{1,10}=10.8 ; p=0.008\right)$. Mean (SE) stop reaction time, omission errors and commission errors in every treatment condition are shown in Figure 3.

Overall, ratings of subjective high were significantly affected by THC $\left(\mathrm{F}_{2,18}=29.77 ; p=0.000\right)$ and THC $\times$ Time after smoking $\left(\mathrm{F}_{4,16}=5.62 ; p=0.004\right)$. Separate contrasts revealed that both doses of THC significantly increased feelings of 'high' $(p=0.000)$. Mean ratings of subjective high in every treatment condition are shown in Figure 4.

There were no effects of THC on performance in the Iowa gambling task. Mean (SE) net scores (advantageous disadvantageous choices) following placebo, THC250 and THC500 were 19.0 (5.5), 12.2 (7.0), and 17.0 (7.3), respectively.

\section{Pharmacokinetics}

Mean (SD) serum THC concentrations at $5 \mathrm{~min}, 1,3$ and $5 \mathrm{~h}$ were, respectively, 93.6 (63.9), 10.61 (5.5), 3.0 (1.7), 1.3 (0.7) $\mathrm{ng} / \mathrm{ml}$ after smoking THC500 and 57.3 (47.9), 5.8 (3.8), $1.7(0.8), 0.7(0.5) \mathrm{ng} / \mathrm{ml}$ after smoking THC250. THC 


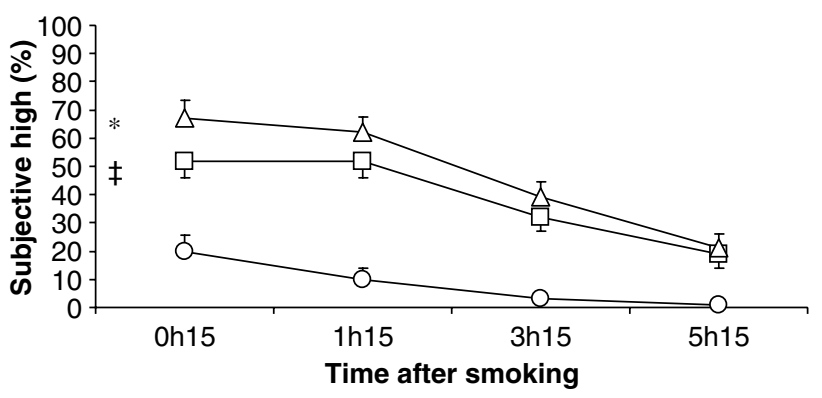

Figure 4 Mean (SE) subjective high rated as a percentage of the maximum ever experienced in each treatment condition as a function of time after smoking. Legend: THC $500=\triangle$; THC 250= $\square ;$ PLA $=0$. Symbols indicate significant $(p<0.05)$ contrasts between THC500 and PLA $(*)$ and between THC250 and PLA ( $\ddagger)$

concentrations were dose related as these were higher after THC500 as compared to THC250 $\left(\mathrm{F}_{1,19}=15.9 ; p=0.001\right)$.

\section{DISCUSSION}

The present study demonstrates the acute effects of smoking high-potency marijuana over a $6 \mathrm{~h}$ period. In terms of cognition, impulse control and psychomotor function, impairment was induced by both doses of marijuana, that is 250 and $500 \mu \mathrm{g} / \mathrm{kg}$ THC, in a dose-related manner. Impairments were most pronounced in the first $2 \mathrm{~h}$ after smoking but were still measurable at $6 \mathrm{~h}$ post dosing. The present data demonstrate that high doses of THC can negatively impact neuropsychological performance domains that have previously been suggested to be relatively insensitive to cannabis intoxication (Hart et al, 2001; Robbe, 1994; Heishman et al, 1997; Fant et al, 1998; Smiley, 1999; Sexton et al, 2000).

Cognitive function as assessed by the Tower of London was negatively affected by marijuana. The Tower of London is a decision making task that measures executive function and planning. The total number of correct decisions and planning time are its main performance measures. The number of correct decisions significantly decreased in a dose-related manner after both doses of THC. Impairment after both doses was prominent at $30 \mathrm{~min}$ and $1 \frac{1}{2} \mathrm{~h}$ postsmoking and persisted for hours. The latter was apparent from the statistical analysis of variance that failed to reveal a significant interaction between THC and Time after smoking. When assessed at $5 \frac{1}{2} \mathrm{~h}$ post smoking, the number of correct decisions was still less after THC as compared to placebo, particularly after the highest dose of THC. Planning time in the Tower of London task, however, was not affected by THC. This indicates that subjects did not try to compensate decision-making deficits by increasing the time needed to solve the cognitive problems at hand. Apparently, subjects did not change their performance strategy during the Tower of London task while under the influence of THC. THC has been previously found to increase error rates in several other tasks, for example, choice reaction time and digit cancellation, while leaving speed of performance unaffected (Curran et al, 2002).

Results from the Tower of London task are in sharp contrast with those by Hart et al (2001). They reported that acute smoked marijuana produced no effect on accuracy measures of cognitive flexibility, mental calculation and reasoning. These measures and those from the Tower of London are in theory highly related, as they all measure complex cognition or executive function. Hart et al (2001) explained the lack of marijuana effect in their study by the high degree of smoking experience of their marijuana subjects. All were heavy marijuana users who smoked marijuana on a daily basis and might have developed tolerance to many marijuana related cognitive effects. In the present study, heavy daily users of marijuana were not included in order to exclude confounding by residual impairment of recent THC use shown to persist in abstinent marijuana users (Fried et al, 2005; Haney et al, 1999; Nicholson et al, 2004; Pope et al, 2001). Subjects in the present study, thus, were light marijuana users that may have been more sensitive to THC effects as compared to the heavy daily users. Yet, a more important distinction may be the amount of THC smoked by the present subjects. The lowest THC dose in the current study was comparable to the highest dose in the study by Hart et al (2001) and our highest dose was even twice as high. In the present study, a relatively low effect size $(0.16)$ was found for performance impairment in the Tower of London after the lowest THC dose. Yet after the highest dose, the effect size rose to 0.40 . In other words, the strength of the association between cognitive impairment and THC was 2.5 times higher after doubling the dose. These data indicate that THC effects on cognitive function may be relatively small in doses up to $250 \mu \mathrm{g} / \mathrm{kg}$ but may become very substantial at higher doses.

The effect of marijuana on tracking performance was very clear-cut and as expected. Both doses produced dose-related tracking impairment, which was most evident at $15 \mathrm{~min}$ and $1 \frac{1}{4} \mathrm{~h}$ postsmoking. Tracking impairment persisted continuously for hours and was still measurable at $3 \frac{1}{4}$ and $5 \frac{1}{4} \mathrm{~h}$ postsmoking. Effect size associated with tracking impairment after the lowest dose of THC was rather low (0.22) but increased to 0.46 after the highest dose. The relatively low effect size after THC $250 \mu \mathrm{g} / \mathrm{kg}$ may be one of the reasons why some studies have failed to find any significant change in tracking performance or related psychomotor measures (Fant et al, 1998; Heishman et al, 1997; Robbe, 1994) after comparable or lower doses of THC. THC-induced impairment of tracking performance is of particular importance to the area of traffic safety research. The Critical tracking task is one of the few psychomotor tasks measuring 'skills related to driving' that actually has been shown to possess a moderate correlation to real-life driving as measured in on-the-road tasks (Ramaekers, 2003). In fact, THC has previously been shown to produce dose related tracking impairment in actual driving tests as well (Ramaekers et al, 2000; Robbe, 1994).

Another goal of this study was to determine whether marijuana increases impulsive behavior and risk taking by means of the Stop signal task and the Iowa gambling task, respectively. The Stop signal task is designed to measure motor impulsivity as defined by the inability to inhibit a response in a rapid response model. The Iowa gambling task measures decision making or risk sensitivity as defined by the inability to anticipate and reflect on the consequences of a choice prior to a decision. Marijuana significantly increased stop reaction time in the Stop signal 
task, that is, the time necessary to inhibit a precued response in No go trials, while leaving reaction time in Go trials unaffected. This suggests that the effect of marijuana was specific to response inhibition and not a consequence of a general slowing of reaction time performance. Marijuana's impairing effect on stop reaction time was particularly prominent after the high dose of THC. That dose increased stop reaction time by about $60-70 \mathrm{~ms}$ at $15 \mathrm{~min}$ and $1 \frac{1}{4} \mathrm{~h}$ after smoking. THC-induced increments in stop reaction time have previously also been reported by McDonald et al (2003). Their Stop signal paradigm, however, included no proportional measure of inhibition failure as the delays to the stop signal were individually adjusted to produce a constant error rate of about $50 \%$ during all treatments. In the present study, stop signal delays were always fixed and commission errors (inhibition errors) and omission errors (false alarms) were taken as additional dependant measures. THC significantly increased the number of commission and omission errors throughout the $6 \mathrm{~h}$ period post-smoking. The concurrent increase in stop reaction time and errors of commission after THC are in line with predictions from the race model of inhibitory control (Logan et al, 1984; Logan, 1994). This model proposes that the response to stop signal trials is defined by two parallel processes: execution of a motor action in response to a signal and inhibition of a motor action in response to stop signal. Crucial to the outcome of the race is the speed of both processes. Response inhibition will fail if the time required to inhibit exceeds the time to complete a motor response at the time of the stop signal. Increments in the time needed to inhibit a response will thus automatically lead to a higher proportion of inhibition failures or commission errors as observed after THC in the present study. The additional increase in omission errors (false alarms) during Go trials is yet another indication of a reduction in impulse control following THC. Together, these data strongly indicate that THC increases motor impulsivity in a Stop signal paradigm.

THC did not affect performance in the Iowa gambling task. In general, the subjects' performance increased throughout the first parts of the task but then dropped to start levels irrespective of placebo or THC treatment. The task has been repeatedly used for showing decrements in risk sensitivity in neurological, psychiatric as well as drug using populations (Bechara et al, 2001; Bolla et al, 2005; Grant et al, 2000; Lamers et al, 2005). Sensitivity of this task to acute drug effects, however, may be low as the task was never specifically designed for this purpose. In a recent study, the Iowa gambling task was not sensitive to single doses of MDMA and alcohol, even though these drugs did produce significant changes in motor impulsivity as assessed in Stop signal and Go-no go paradigms (Ramaekers and Kuypers, 2006). Moreover, the Iowa gambling task was only administered once at $1 \mathrm{~h}$ postsmoking as only three parallel versions of the task were available. The possibility for conducting repeated measures, therefore, was limited. Perhaps, the sensitivity of the Iowa gambling task might have been higher if the task had been administered closer to smoking when THC blood levels would have been higher. Yet, THC levels seen at $1 \mathrm{~h}$ postsmoking, that is, 5 and $10 \mathrm{ng} / \mathrm{nl}$ after the low and high dose of THC, respectively, have previously been associated with impair- ments in a range psychomotor and cognitive tasks (Ramaekers et al, 2004).

Other tasks that might be related to the Iowa gambling task or measure a overlapping psychological domain have shown mixed results with regard to cannabis intoxication. McDonald et al (2003) failed to show any effect of THC on cognitive impulsivity as assessed in a Delay discounting task. Performance on this task is significantly correlated to performance on the Iowa gambling task (Monterosso et al, 2001). However, as with the Iowa gambling tasks, McDonald et al (2003) also questioned the sensitivity of the Delay discounting task to drug-induced state changes in impulsive behavior. THC did increase risk tasking in a two choice risk taking task, in which subjects repeatedly chose one out of two buttons, each associated with a risky or nonrisky payoff contingency (Lane et al, 2005). It is unknown at present whether performance in this risk-taking task is correlated to performance in the Iowa gambling task or the Delay discounting task.

In conclusion, high-potency marijuana was shown to consistently impair executive function as assessed in the Tower of London task. Motor control was likewise impaired as indicated by a decrement in tracking performance in the Critical tracking task and a decrease in motor impulse control during Stop signal task performance. Impairments lasted up to $6 \mathrm{~h}$ post-smoking and were most prominent after THC $500 \mu \mathrm{g} / \mathrm{kg}$. Effect sizes for performance impairments produced by THC $250 \mu \mathrm{g} / \mathrm{kg}$ were relatively low but increased by about a factor 2 in case of THC $500 \mu \mathrm{g} / \mathrm{kg}$. Use of higher doses of THC in controlled studies thus may offer a more reliable indication of cannabis-related performance impairment as compared to lower doses of THC that have traditionally been used in performance studies.

\section{ACKNOWLEDGEMENTS}

This study was supported by grants from the German Federal Police Academy and the German Society against Alcohol Drugs and Driving ('Bund gegen Alkohol und Drogen im Straßenverkehr'). We thank Anita van Oers, Janneke Guyaux and Roland Otten for their contributions to study logistics and data collection. We are grateful to Elke Runow, Volker Schwarz, Werner Pogoda and Markus Düchardt for their technical assistance. We thank Chip Walls for his literature 'search engine'.

\section{REFERENCES}

Ameri A (1999). The effects of cannabinoids on the brain. Prog Neurobiol 58: 315-348.

Bechara A, Damasio H, Damasio AR (2000). Emotion, decision making and the orbitofrontal cortex. Cereb Cortex 10: 295-307.

Bechara A, Dolan S, Denburg N, Hindes A, Anderson SW, Nathan PE (2001). Decision-making deficits, linked to a dysfunctional ventromedial prefrontal cortex, revealed in alcohol and stimulant abusers. Neuropsychologia 39: 376-389.

Bolla KI, Eldreth DA, Matochik JA, Cadet JL (2005). Neural substrates of faulty decision-making in abstinent marijuana users. Neuroimage 26: 480-492.

Chait LD (1989). Delta-9-tetrahydrocannabinol content and human marijuana self-administration. Psychopharmacology (Berl) 98: $51-55$. 
Chait LD, Burke KA (1994). Preference for high- versus lowpotency marijuana. Pharmacol Biochem Behav 49: 643-647.

Curran HV, Brignell C, Fletcher S, Middleton P, Henry J (2002). Cognitive and subjective dose-response effects of acute oral Delta 9-tetrahydrocannabinol (THC) in infrequent cannabis users. Psychopharmacology (Berl) 164: 61-70.

D'Souza DC, Perry E, MacDougall L, Ammerman Y, Cooper T, Wu YT et al (2004). The psychotomimetic effects of intravenous delta-9-tetrahydrocannabinol in healthy individuals: implications for psychosis. Neuropsychopharmacology 29: 1558-1572.

ElSohly MA (2004). Marijuana potency monitoring project. National Center for Natural Products Research, School of Pharmacy, University of Mississippi.

Fant RV, Heishman SJ, Bunker EB, Pickworth WB (1998). Acute and residual effects of marijuana in humans. Pharmacol Biochem Behav 60: 777-784.

Fillmore MT, Rush CR, Hays L (2002). Acute effects of oral cocaine on inhibitory control of behavior in humans. Drug Alcohol Depend 67: 157-167.

Fried PA, Watkinson B, Gray R (2005). Neurocognitive consequences of marihuana - a comparison with pre-drug performance. Neurotoxicol Teratol 27: 231-239.

Grant S, Contoreggi C, London ED (2000). Drug abusers show impaired performance in a laboratory test of decision making. Neuropsychologia 38: 1180-1187.

Hall W, Solowij N (1998). Adverse effects of cannabis. Lancet 352: 1611-1616.

Hampson RE, Deadwyler SA (1999). Cannabinoids, hippocampal function and memory. Life Sci 65: 715-723.

Haney M, Ward AS, Comer SD, Foltin RW, Fischman MW (1999). Abstinence symptoms following smoked marijuana in humans. Psychopharmacology (Berl) 141: 395-404.

Hart CL, van Gorp W, Haney M, Foltin RW, Fischman MW (2001). Effects of acute smoked marijuana on complex cognitive performance. Neuropsychopharmacology 25: 757-765.

Heishman SJ, Arasteh K, Stitzer ML (1997). Comparative effects of alcohol and marijuana on mood, memory, and performance. Pharmacol Biochem Behav 58: 93-101.

Iversen L (2003). Cannabis and the brain. Brain 126: 1252-1270.

Jex HR, McDonnell JD, Phatak AV (1966). A 'critical'tracking task for manual control research. IEEE 7: 138-145.

King LA, Carpentier C, Griffiths P (2004). An Overview of Cannabis Potency in Europe. European Monitoring Centre for Drugs and Drug Addiction: Lisbon.

King LA, Carpentier C, Griffiths P (2005). Cannabis potency in Europe. Addiction 100: 884-886.

Korf DJ, Wouters M, Benschop A, Van Ginkel P (2004). Sterke Wiet. Criminologisch Instituut Bongers, University of Amsterdam, Rozenberg Publishers: Amsterdam.

Lamers CTJ, Bechara A, Rizzo M, Ramaekers JG (2005). Cognitive function and mood in MDMA/THC users, THC users and nondrug using controls. J Psychopharmacol 20: 302-311.

Lane SD, Cherek DR, Tcheremissine OV, Lieving LM, Pietras CJ (2005). Acute marijuana effects on human risk taking. Neuropsychopharmacology 30: 800-809.

Leweke M, Kampmann C, Radwan M, Dietrich DE, Johannes S, Emrich HM et al (1998). The effects of tetrahydrocannabinol on the recognition of emotionally charged words: an analysis using event-related brain potentials. Neuropsychobiology 37: 104-111.

Lichtman AH, Varvel SA, Martin BR (2002). Endocannabinoids in cognition and dependence. Prostaglandins Leukot Essent Fatty Acids 66: 269-285.
Liguori A, Gatto CP, Jarrett DB (2002). Separate and combined effects of marijuana and alcohol on mood, equilibrium and simulated driving. Psychopharmacology (Berl) 163: 399-405.

Liguori A, Gatto CP, Jarrett DB, McCall WV, Brown TW (2003). Behavioral and subjective effects of marijuana following partial sleep deprivation. Drug Alcohol Depend 70: 233-240.

Logan GD, Cowan WB, Davis KA (1984). On the ability to inhibit simple and choice reaction time responses: a model and a method. J Exp Psychol Hum Percept Perform 10: 276-291.

Logan GDI (1994). On the ability to inhibit though and action: a users'guide to the stop signal paradigm. In: Dagenbach D, Carr $\mathrm{TH}$ (eds). Inhibitory Processes in Attention, Memory and Language. Academic Press: San Diego. pp 189-239.

McDonald J, Schleifer L, Richards JB, de Wit H (2003). Effects of THC on behavioral measures of impulsivity in humans. Neuropsychopharmacology 28: 1356-1365.

Monterosso J, Ehrman R, Napier KL, O'Brien CP, Childress AR (2001). Three decision-making tasks in cocaine-dependent patients: do they measure the same construct? Addiction 96: $1825-1837$.

Nicholson AN, Turner C, Stone BM, Robson PJ (2004). Effect of Delta-9-tetrahydrocannabinol and cannabidiol on nocturnal sleep and early-morning behavior in young adults. J Clin Psychopharmacol 24: 305-313.

Pope Jr HG, Gruber AJ, Hudson JI, Huestis MA, Yurgelun-Todd D (2001). Neuropsychological performance in long-term cannabis users. Arch Gen Psychiatry 58: 909-915.

Ramaekers JG (2003). Antidepressants and driver impairment: empirical evidence from a standard on-the-road test. J Clin Psychiatry 64: 20-29.

Ramaekers JG, Berghaus G, van Laar M, Drummer OH (2004). Dose related risk of motor vehicle crashes after cannabis use. Drug Alcohol Depend 73: 109-119.

Ramaekers JG, Kuypers KP (2006). Acute Effects of 3,4-Methylenedioxymethamphetamine (MDMA) on Behavioral Measures of Impulsivity: Alone and in Combination with Alcohol. Neuropsychopharmacology 31: 1048-1055.

Ramaekers JG, Robbe HW, O'Hanlon JF (2000). Marijuana, alcohol and actual driving performance. Hum Psychopharmacol 15: 551-558.

Robbe HWJ (1994). Influence of Marijuana on Driving. Institute for Human Psychopharmacology, University of Limburg.

Sexton BF, Turnbridge RJ, Brook-Carter N, Jackson PG, Wright KA, Strak MM et al (2000). The Influence of Cannabis on Driving. Transport Research Foundation Limited (TRL): United Kingdom.

Shallice T (1982). Specific Impairments of Planning. Phil. Trans. of the Royal Society of London: London. pp 199-209.

Smiley A (1999). On road and driving simulator studies. In: Kalant $\mathrm{H}$, Corrigal W, Hall W, Smart R (eds). The Health Effects of Cannabis. Addiction Research Foundation: Toronto.

Steinmeyer S, Bregel D, Warth S, Kraemer T, Moeller MR (2002). Improved and validated method for the determination of Delta(9)-tetrahydrocannabinol (THC), 11-hydroxy-THC and 11-nor-9-carboxy-THC in serum, and in human liver microsomal preparations using gas chromatography-mass spectrometry. J Chromatogr B Analyt Technol Biomed Life Sci 772: 239-248.

Veale DM, Sahakian BJ, Owen AM, Marks IM (1996). Specific cognitive deficits in tests sensitive to frontal lobe dysfunction in obsessive-compulsive disorder. Psychol Med 26: 1261-1269. 